\title{
Evaluation of the Correlation between Echocardiographic Findings and Serum Ferritin in Thalassemia Major Patients
}

\author{
Mohammad Reza Khalilian ${ }^{1}$, Roozbeh Moghaddar ${ }^{2}$, Abdolrahman Emami-Moghadam ${ }^{1}$, Bijan Keikhaei ${ }^{3}$, Ali \\ Amin-Asnafi ${ }^{3} \&$ Mohammad Bahadoram ${ }^{3,4}$ \\ ${ }^{1}$ Department of Pediatric Cardiology, School of Medicine, Shahid Beheshti University of Medical Sciences, \\ Tehran, Iran \\ ${ }^{2}$ Department of Pediatric, School of Medicine, Ahvaz Jundishapur University of Medical Sciences, Ahvaz, \\ Iran \\ ${ }^{3}$ Health Institute, Research Center for Thalassemia and Hemoglobinopathy, Ahvaz Jundishapur University of \\ Medical Sciences, Ahvaz, Iran \\ ${ }^{4}$ Medical Student Research Committee, Ahvaz Jundishapur University of Medical Sciences, Ahvaz, Iran \\ Correspondence: Mohammad Reza Khalilian, Department of Pediatric Cardiology, School of Medicine, Shahid \\ Beheshti University of Medical Sciences, Tehran, Iran. Tel: 98-916-118-3264. E-mail: \\ Khalilian.mr@ajums.ac.ir
}

Received: February 19, 2016 Accepted: March 26, 2016 Online Published: April 29, 2016

doi:10.5539/gjhs.v8n12p190 URL: http://dx.doi.org/10.5539/gjhs.v8n12p190

\begin{abstract}
Introduction: Thalassemia is a disorder that affects beta globin gene production and the resultant need for erythrocyte transfusions puts the patient at risk for iron loading, especially cardiac iron loading. Cardiac complications are the most serious ones accompanied by morbidity and mortality. The most harm to the heart is caused by iron overload. Ferritin is generally associated with the amount of stored iron in the body. The aim of this study was to investigate the relationship between echocardiographic findings and serum ferritin level.

Materials \& Methods: 107 patients with thalassemia major were enrolled in this prospective analytical study. Serum ferritin levels and echocardiographic findings (diastolic, systolic, pulmonary artery pressure, valvular dysfunctions) were assessed. The data were analyzed by spearman statistical test.
\end{abstract}

Results: Serum ferritin levels of the thalassemia major patients in the study were $2419.13 \pm 1772.65 \mathrm{ng} / \mathrm{ml}$. there wasn't any significant relationship between echocardiographic findings and serum ferritin level.

Conclusion: Although our findings didn't support the association between ferritin level and echocardiographic data but we suggest serial cardiac assessment to prevent the effect of increasing iron on the heart.

Keywords: thalassemia major, echocardiography, ferritin, iron overload, pulmonary wedge pressure

\section{Introduction}

Thalassemia is an autosomal recessive disorder. Today, thalassemia treatment is being done in the most optimal way. It is believed that $7 \%$ of people worldwide are carriers of thalassemia gene who are divided into two main groups of alpha and beta (Rund \& Rachmilewitz, 2005). Thalassemia is largely prevalent around Mediterranean Sea, East Asia, parts of South and West Africa and Saudi Arabia. The estimated prevalence of beta thalassemia is $16 \%$ in Cyprus, 3-14\% in Thailand and 3-8\% in India, Pakistan, Bangladesh and China. Prevalence is low in black African persons $(0.9 \%)$ and Northern Europe $(0.1 \%$ ) (Liao et al., 2005). In the last study conducted in Iran it was estimated that about 6 to 7 percent of persons are carriers of thalassemia with more prevalence in the north and south and less prevalence in central areas (Karimi et al., 2011). Thalassemia constitutes a syndrome with many complications chiefly cardiovascular diseases that comprise cardiomyopathy, thrombotic events and pulmonary hypertension (Aessopos et al., 2005). Cardiac complications are the most serious ones accompanied by morbidity and mortality (Olivieri, 1999). The most harm to the heart is caused by iron overload. Mechanisms responsible for raising iron levels consist of blood transfusion, increased iron intake through intestinal absorption, peripheral hemolysis and damaged red blood cells in the first stages of life (Modell et al., 2000). Normally, each blood unit contains $250 \mathrm{mg}$ of iron. 1-2 $\mathrm{mg}$ of iron is excreted daily in humans. As a result, iron is stored 
routinely which can cause harm to various body organs. Iron may deposit in all layers of the heart but the deposits are more likely to occur in the external layer (epicardium) than the internal layer (endoocardium). Deposition of iron in myocardium can cause both hypertrophy and dilated heart chambers (Tanner et al., 2006; Isma'eel et al., 2008). The entire electrical system of the heart will be engaged just like the muscular system. Cardiac disorders in thalassemia patients are divided into four categories consisting of: impairment of the heart muscle, cardiac arrhythmia, pulmonary hypertension and pericardial effusion (Borgna-Pignatti et al., 2006). Clinical manifestations of cardiac disorders in thalassemia patients include tachycardia, dyspnea during exercise, dyspnea at rest, sleep disorders, swelling of the lower extremities, chronic fatigue, decreased appetite, cough, nocturia and disorders of consciousness. Common mechanisms of myocardial damage in these patients include the direct effect of free radicals and iron. Additionally, vascular complications caused by hemolysis and free radicals, gland disorders (hypothyroidism, diabetes), cardiac arrhythmias, infections, increased activity of the coagulation system, valvular dysfunctions and various drugs aid in myocardial damage (Cunningham et al., 2004). Cardiac output gradually increases in thalassemia patients over time and results in heart failure in the form of high cardiac output. Valvular dysfunctions manifestations appear as thickness, calcium deposits, and valve structure damage (Derchi et al., 1992). Echocardiography is an appropriate non-invasive diagnostic method that allows measuring the size of heart chambers, systolic and diastolic volume, structure and function of valves, calculation of pulmonary arterial pressure, Thrombosis in the cavities, the study of structure and function of pericardium and the motion of various wall muscles (Aessopos et al., 2007; Silvilairat et al., 2008; Walker \& Nair, 2010). One method for evaluating iron in thalassemia patients is measuring serum Ferritin. This is a simple and feasible method in most laboratories. Ferritin is generally associated with the amount of stored iron in the body. However, Ferritin is not without limitations as it is a protein found only in acute phases. Inflammation, hepatitis and liver damage may give it a false boost. Due to its variable nature, ferritin level measurement should be done 2-3 times a year and the mean level should be used. Several studies have demonstrated the link between ferritin level and patients' prognosis (Ashena et al., 2007). Ferritin is still worthy as a marker in the prognosis of thalassemia patients. Numerous studies conducted over a decade have illustrated that the risk of cardiac disease and death plummets in patients with ferritin levels lower than $2500 \mathrm{ng} / \mathrm{ml}$. Nonetheless, it is emphasized to keep the serum ferritin level below $1000 \mathrm{ng} / \mathrm{ml}$ in patients (Bosi et al., 2003). Ferritin test is still the most available means for follow-up and altering the dose of chelation drugs in many centers. Advantages of ferritin test comprise simplicity, inexpensiveness, availability and monitoring of chelation therapy. In this study, we evaluated serum ferritin levels in patients with thalassemia major and functional class I with the findings of echocardiography (systolic, diastolic, pulmonary arterial pressure). We wanted to determine the relationship between ferritin levels and echo findings and cardiac function. We set to find out whether serum ferritin can be appointed as a marker for patients' follow-up when cardiac function is engaged. The aim of this study was to evaluate the relationship between echocardiographic findings and serum ferritin levels in patients with thalassemia major.

\section{Materials and Methods}

\subsection{Study Design}

This study was done as a prospective analytical study. 107 thalassemia major patients participated in the study. The patients had all functional class I (no limitation in doing exercises and daily activities) and were evaluated for ferritin level. The evaluation was performed twice with one month in between. They had their echocardiography by a pediatric cardiologist in view of diastolic and systolic disorders, pulmonary artery pressure and valvular dysfunctions.

\subsection{Study Population}

The population of the study was all the patients with thalassemia major who had attended the center for thalassemic patients in south west of Iran and had a medical record there. All the patients included in the study had normal ranges of creatinine and cardiac enzymes. It should be noted that patients with chronic kidney problems or functional class II or above or patients who were under heart failure treatment were excluded from the study.

The variables for the study were gender, age, serum ferritin levels, echocardiographic findings (diastolic, systolic, pulmonary artery pressure, valvular dysfunctions). The necessary information was collected through the patients' history via hospital records and patient reports during the time stipulated.

Echocardiographic findings included systolic function (ejection fraction \& shortening fraction) for left ventricle and Tricuspid Annular Plain Systolic Excursion (TAPSE) for right ventricle. Other echo findings such as diastolic function (E/A ratio of the mitral valve), pulmonary arterial pressure and valvular involvement were also 
considered. Left ventricular systolic dysfunction was determined by ejection fraction $<50 \%$ and shortening fraction $<28 \%$ in a classification in which ejection fraction of $40-50 \%$ was categorized as mild impairment and ejection fraction $30-40 \%$ moderate impairment and ejection fraction $<30 \%$ as severe impairment. Right ventricular systolic dysfunction was determined by TAPSE $<1.5 \mathrm{~cm}$ in a classification in which patients with TAPSE 1.2-1.5 were categorized as mild impairment and TAPSE 1-1.2 moderate impairment and TAPSE $<1$ as severe impairment for right ventricle. Left ventricular dilatation was determined by End Point Septal Separation (EPSS) $>8 \mathrm{~mm}$. Diastolic dysfunction was defined by E/A ration $>2$ or $<$. Pulmonary hypertension was described as mean pulmonary arterial pressure $>25 \mathrm{mmHg}$ and systolic pulmonary arterial pressure $>36 \mathrm{mmHg}$ (Quinones et al., 2002). Valvular involvement indicates one or multiple heart valves involvement revealed by echocardiography. Echocardiography was performed by a pediatric cardiologist with a vivid3 device with a probe of 3-5 MHz. During the ferritin measurement, the patients were free from inflammation and infection. Ferritin was measured twice with a one-month interval in a laboratory center by a ferritin checker device called Sunrise Touchscreen made by Tecan co. and the mean level was recorded.

\subsection{Statistical Analysis}

Categorization of the data was done by SPSS18. Once the date was collected, we used frequency distribution table for describing the data and Spearman statistical test for analyzing the data. P values of 0.05 or less was considered statistically significant.

\section{Results}

Out of 107 patients entered into the study, 52 were male and 55 were female. The mean patient age was $19.57 \pm 7.97$ years. The mean patient weight was $41.95 \pm 20.11 \mathrm{~kg}$ and the patients' mean body mass index (BMI) was $20.11 \pm 2.95$. Positive familial history of thalassemia was found in 38 patients $(35.51 \%)$ of which 33 patients $(86.8 \%)$ had it in their first-degree relatives. Serum ferritin levels of the thalassemia major patients in the study were $2419.13 \pm 1772.65 \mathrm{ng} / \mathrm{ml}$. Left ventricular systolic dysfunction was found in 63 patients $(58.9 \%)$ of which 30 patients $(78.9 \%)$ had mild and 8 patients $(21.1 \%)$ had moderate impairment. Right ventricular systolic dysfunction was found in 67 patients $(62.6 \%)$ of which 62 patients $(92.5 \%)$ had mild and 4 patients $(6 \%)$ had moderate and 1 patient $(1.5 \%)$ had severe impairment. 77 patients $(72 \%)$ had valvular dysfunction. Pulmonary hypertension was recorded in 36 patients (33.6\%). In 53 patients (49.5\%) left ventricular dilatation was reported. Evaluation of the relationship between ferritin level and ejection fraction in echocardiography via spearman test displayed no significant relationship $(\mathrm{r}=0.15$, Pvalue $=0.12)$ (Figure 1). Further, Spearman test showed no relationship between serum ferritin level and $\mathrm{E} / \mathrm{A}$ ratio of the mitral valve ( $\mathrm{r}=0.147$, Pvalue $=0.131$ ) (Figure 2).

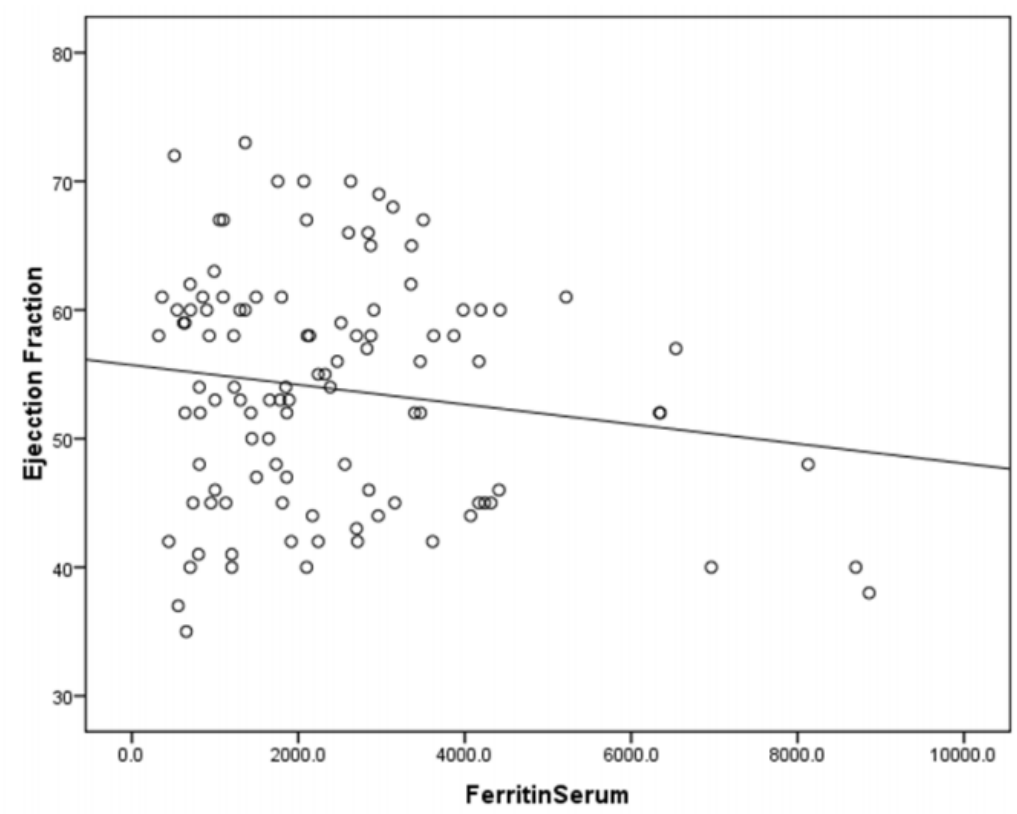

Figure 1. Relationship between serum ferritin level and ejection fraction in echocardiography $(\mathrm{r}=-0.15$,

$$
\mathrm{P}_{\text {value }}=0.12 \text { ) }
$$




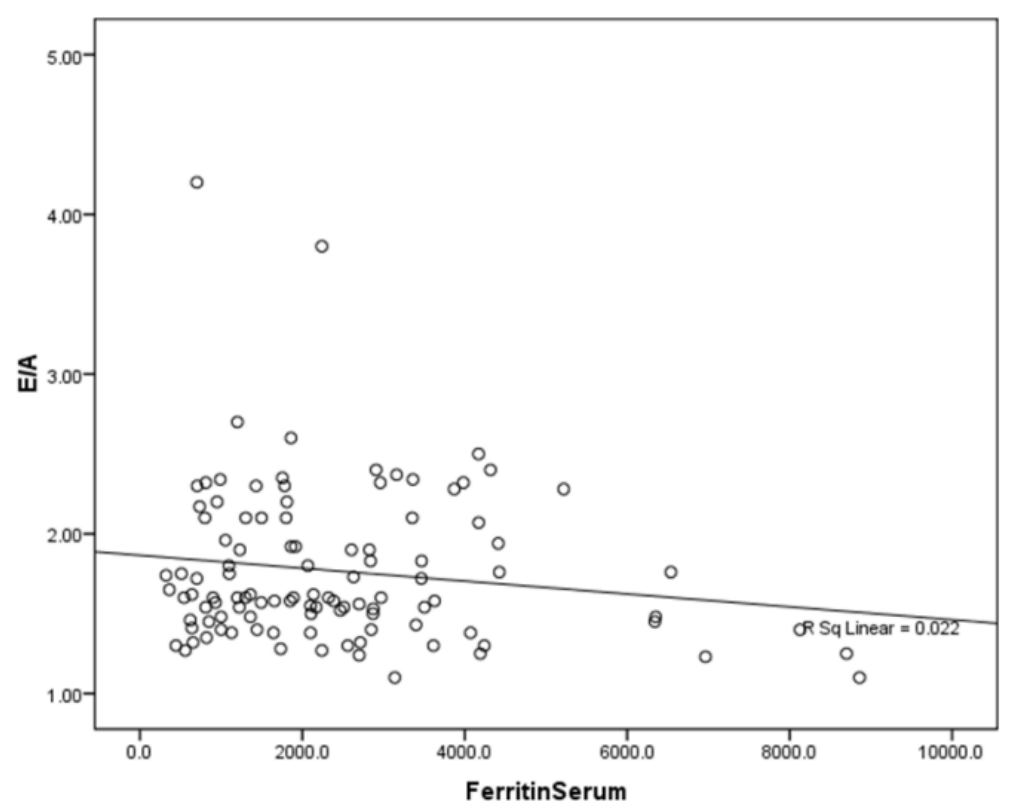

Figure 2. Relationship between serum ferritin level and $\mathrm{E} / \mathrm{A}$ ratio of the mitral value $\left(\mathrm{r}=-0.147, \mathrm{P}_{\text {value }}=0.131\right)$

Through this test, we got no significant relationship between TAPSE level and serum ferritin level $(\mathrm{r}=-0.156$, Pvalue $=0.205$ ) (Figure 3). We also got no significant link between EPSS level and serum ferritin level $(\mathrm{r}=-0.046$, Pvalue $=0.641)$ (Figure 4).

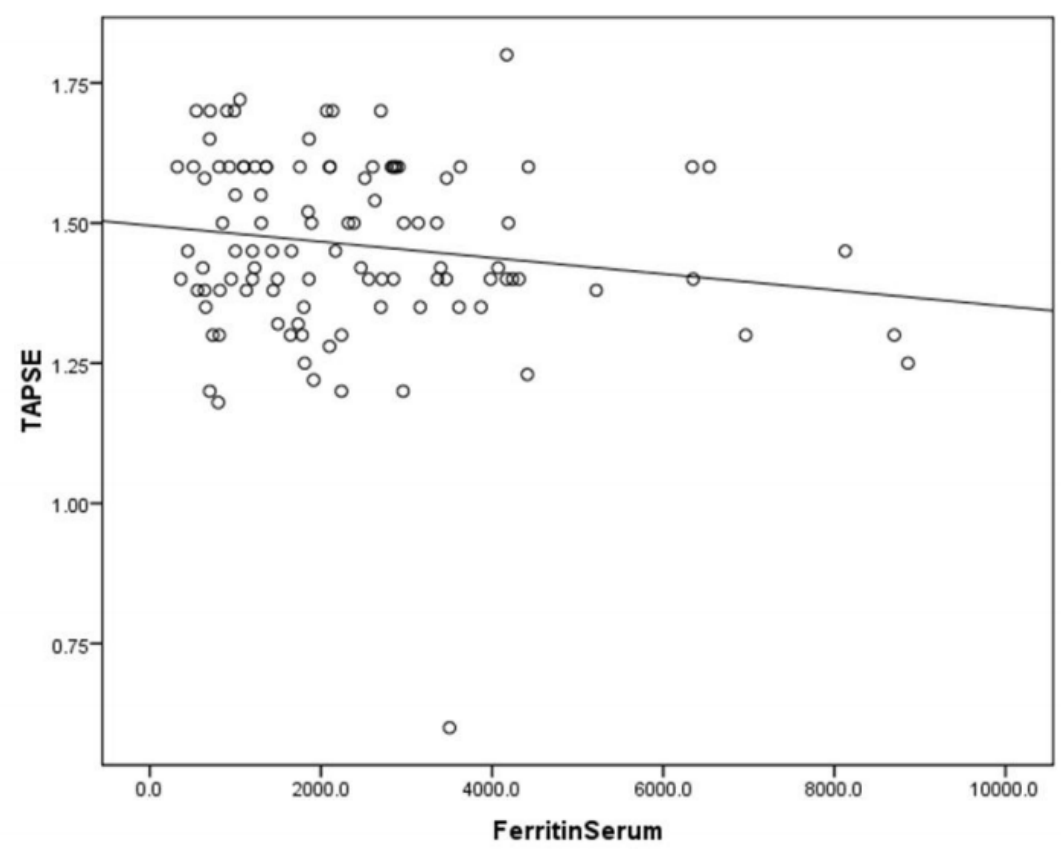

Figure 3. Relationship between TAPSE level and serum ferritin level $\left(r=-0.156, P_{\text {value }}=0.205\right)$ 


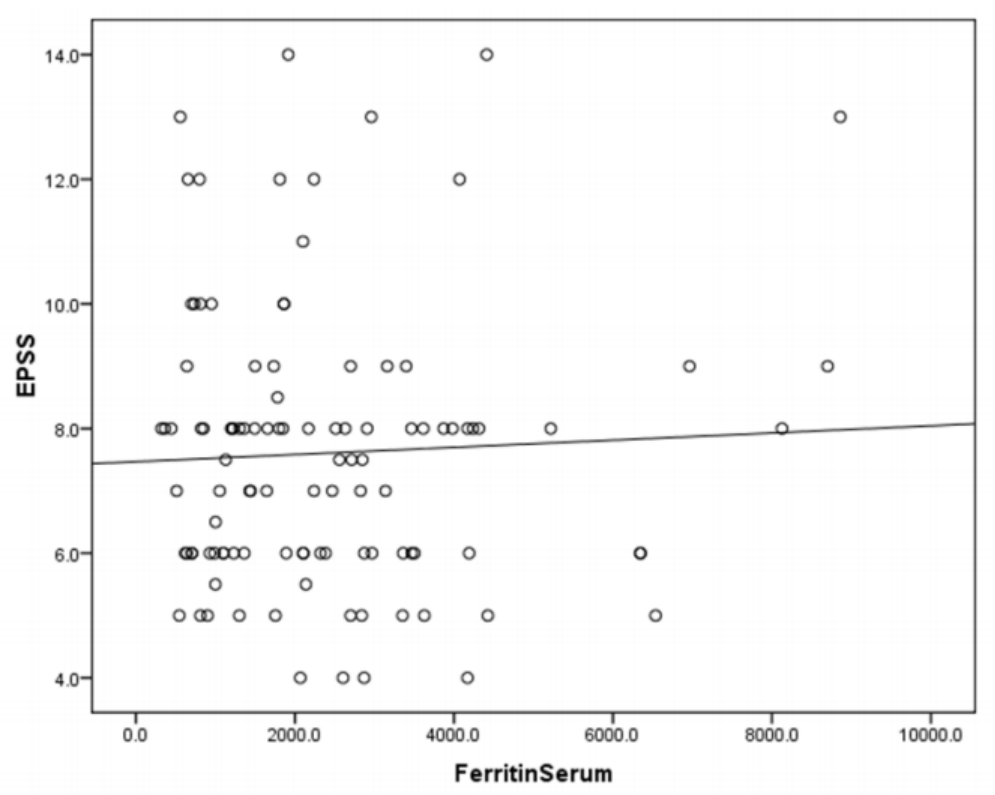

Figure 4. Relationship between EPSS level and serum ferritin level $\left(\mathrm{r}=-0.046, \mathrm{P}_{\text {value }}=0.641\right)$

\section{Discussion}

LV dysfunction is probably due to long exposure to iron overload in the heart. A significant relationship has been demonstrated between myocardial iron overload and decreased LV function (Tanner et al., 2006). However, Bosi et al. found a weak but significant correlation between left ventricular ejection fraction and serum ferritin concentration, where patients with a high ferritin concentration $(>2500 \mathrm{ng} / \mathrm{ml})$ had a lower ejection fraction than patients with a low ferritin concentration $(<1000 \mathrm{ng} / \mathrm{ml})$ (Bosi et al., 2003). Echocardiographic studies have shown cardiovascular prognosis in $\beta$-thalassemia patients to be excellent if serum ferritin is $<2500 \mathrm{ng} / \mathrm{ml}$. Serum ferritin $<2500 \mathrm{ng} / \mathrm{ml}$ is considered to be safe (Olivieri, 1999). Some studies illustrated negative correlation between serum ferritin and left ventricular ejection fraction (Borgna-Pignatti et al., 2004; Montazare et al., 2011). Numerous studies have found lower ferritin levels to reduce complication events resulting in better prognosis (Telfer et al., 2000; Borgna-Pignatti et al., 2004). Several reports didn't find any statistically significant relationship between serum ferritin concentration and systolic and diastolic indices (Yaprak et al., 1998; Ashena et al., 2007). Their results were consistent with our findings and displayed no significant correlation between ventricular ejection fraction and serum ferritin. Approximately 19\% of regularly transfused and chelated thalassemia major patients need cardiovascular drug therapy. This subgroup is characterized by a dilated and mildly hypokinetic left ventricle when compared with the majority of thalassemia major patients who do not require drug treatment. These data underscore the importance of careful evaluation of cardiac functional status in patients with thalassemia major (Derchi et al., 2011). Thus, it is imperative for thalassemia major patients to have their heart examined and have an echocardiography under cardiologist supervision. Another survey done on 44 patients with major beta thalassemia showed no relationship between left ventricular diastolic function and serum ferritin. Heart disease is the primary determinant of prognosis and survival in $\beta$-thalassemia. Myocardial iron deposition seems to be a major development trigger for heart failure in thalassemia major. With regard to heart failure in $\beta$-thalassemia, patients' prognosis could be improved by intensifying blood transfusions and iron-chelation therapy as well as conventional treatments. These measures are able to raise the level of survival to that observed in the general heart failure population (Kremastinos et al., 2010). A recent study demonstrated a significant correlation between iron overload in the liver and pulmonary artery systolic pressure independent of LV filling pressures (Isma'eel et al., 2008). conventional Doppler echocardiography and tissue Doppler allow for identifying left ventricular diastolic alterations in asymptomatic patients with thalassemia major (Rodrigues et al., 2013). In comparison, another investigation consisting 110 patients with thalassemia intermedia, overall mean ferritin levels were $1657 \pm 1477 \mathrm{ng} / \mathrm{ml}$ which was lower than what we found in the present study $(2419.13 \pm 1772.65 \mathrm{ng} / \mathrm{ml})$ that could be the result of less frequent and incorrect use of iron chelation in our patients (Aessopos et al., 2001). Early detection of the associated complications in beta thalassemia patients is immensely beneficial in reducing the burden of the disease through preventive measures. A significant 
percentage of thalassemia patients have left ventricular dysfunction. This is mainly due to chronic anemia, iron overload and poor compliance with chelation therapy (Hyder et al., 2013). Echocardiographic metrics of systolic and diastolic dysfunction are insensitive but relatively fit for cardiac iron overload; tricuspid regurgitation jet is helpful for identifying pulmonary hypertension. Patients with thalassemia intermedia are particularly vulnerable to pulmonary hypertension because of higher cardiac output, splenectomy, and greater intravascular hemolysis; a majority of patients will develop pulmonary hypertension in middle age (Wood, 2009). Regular assessment of cardiac function may help to improve the quality of life for these patients and may reduce the morbidity and mortality to a great extent. Echocardiogram should be performed annually.

\section{Conclusion}

According to the result of this study there was not any relationship between serum ferritin level and echocardiographic data. Since serum ferritin is an index for level of iron in the body, thus, it's necessary for thalassemia major patients to undergo serial cardiac and echocardiographic evaluations to assess the effect of iron increase on their heart.

\section{Acknowledgments}

This study is part of thesis for Dr. Roozbeh Moghaddar. Special thanks to Ahvaz Jundishapur University of Medical Sciences for the financial support (Thesis Grant No. TH93-13).

\section{Competing Interests Statement}

The authors declare that there is no conflict of interests regarding the publication of this paper.

\section{References}

Aessopos, A., Farmakis, D., Deftereos, S., Tsironi, M., Tassiopoulos, S., Moyssakis, I., \& Karagiorga, M. (2005). Thalassemia heart disease: A comparative evaluation of thalassemia major and thalassemia intermedia. Chest, 127(5), 1523-1530. http://dx.doi.org/10.1378/chest.127.5.1523

Aessopos, A., Farmakis, D., Karagiorga, M., Voskaridou, E., Loutradi, A., Hatziliami, A., ... Loukopoulos, D. (2001). Cardiac involvement in thalassemia intermedia: A multicenter study. Blood, 97(11), 3411-3416. http://dx.doi.org/10.1182/blood.V97.11.3411

Aessopos, A., Giakoumis, A., Fragodimitri, C., Karabatsos, F., Hatziliami, A., Yousef, J., ... Karagiorga, M. (2007). Correlation of echocardiography parameters with cardiac magnetic resonance imaging in transfusion-dependent thalassaemia major. Eur J Haematol, 78(1), 58-65. http://dx.doi.org/10.1111/j. 1600-0609.2006.00770.x

Ashena, Z., Ghafurian, S., \& Ehsani, M. A. (2007). The relation between left ventricular diastolic indices and serum ferritin in thalassemia major. Pediatr Hematol Oncol, 24(1), 3-14. http://dx.doi.org/10.1080/0 8880010600970476

Borgna-Pignatti, C., Cappellini, M. D., De Stefano, P., Del Vecchio, G. C., Forni, G. L., Gamberini, M. R., ... Cnaan, A. (2006). Cardiac morbidity and mortality in deferoxamine-or deferiprone-treated patients with thalassemia major. Blood, 107(9), 3733-3737. http://dx.doi.org/10.1182/blood-2005-07-2933

Borgna-Pignatti, C., Rugolotto, S., De Stefano, P., Zhao, H., Cappellini, M. D., Del Vecchio, G. C., ... Cnaan, A. (2004). Survival and complications in patients with thalassemia major treated with transfusion and deferoxamine. Haematologica, 89(10), 1187-1193.

Bosi, G., Crepaz, R., Gamberini, M. R., Fortini, M., Scarcia, S., Bonsante, E., ... Vaccari, M. (2003). Left ventricular remodelling, and systolic and diastolic function in young adults with beta thalassaemia major: A Doppler echocardiographic assessment and correlation with haematological data. Heart, 89(7), 762-766. http://dx.doi.org/10.1136/heart.89.7.762

Cunningham, M. J., Macklin, E. A., Neufeld, E. J., Cohen, A. R., \& N. Thalassemia Clinical Research. (2004). Complications of beta-thalassemia major in North America. Blood, 104(1), 34-39. http://dx.doi.org/10. 1182/blood-2003-09-3167

Derchi, G., Bellone, P., Forni, G. L., Lupi, G., Jappelli, S., Randazzo, M., Zino, V., \& Vecchio, C. (1992). Cardiac involvement in thalassaemia major: Altered atrial natriuretic peptide levels in asymptomatic patients. Eur Heart J, 13(10), 1368-1372.

Derchi, G., Formisano, F., Balocco, M., Galanello, R., Bina, P., Dessi, C., ... Forni, G. L. (2011). Clinical management of cardiovascular complications in patients with thalassaemia major: A large observational multicenter study. Eur J Echocardiogr, 12(3), 242-246. http://dx.doi.org/10.1093/ejechocard/jeq190 
Hyder, S., Kazmi, U., \& Malik, A. (2013). An Echocardiographic Evaluation of Left Ventricular Function in Patients with Thalassemia Major. J Pak Med Stud, 3(1), 10-15.

Isma'eel, H., Cappellini, M., \& Taher, A. (2008). Chronic transfusion, iron overload and cardiac dysfunction: A multi-dimensional perspective. Br J Cardiol, 15(1), 40-45.

Isma'eel, H., Chafic, A. H., El Rassi, F., Inati, A., Koussa, S., Daher, R., ... Taher, A. (2008). Relation between iron-overload indices, cardiac echo-Doppler, and biochemical markers in thalassemia intermedia. $\mathrm{Am} J$ Cardiol, 102(3), 363-367. http://dx.doi.org/10.1016/j.amjcard.2008.03.066

Karimi, M., Emadmarvasti, V., Hoseini, J., \& Shoja, L. (2011). Major causes of hospital admission in Beta thalassemia major patients in southern Iran. Iran J Pediatr, 21(4), 509-513.

Kremastinos, D. T., Farmakis, D., Aessopos, A., Hahalis, G., Hamodraka, E., Tsiapras, D., \& Keren, A. (2010). Beta-thalassemia cardiomyopathy: History, present considerations, and future perspectives. Circ Heart Fail, 3(3), 451-458. http://dx.doi.org/10.1161/CIRCHEARTFAILURE.109.913863

Liao, C., Mo, Q. H., Li, J., Li, L. Y., Huang, Y. N., Hua, L., ... Xu, X. M. (2005). Carrier screening for alphaand beta-thalassemia in pregnancy: The results of an 11-year prospective program in Guangzhou Maternal and Neonatal hospital. Prenat Diagn, 25(2), 163-171. http://dx.doi.org/10.1002/pd.1079

Modell, B., Khan, M., \& Darlison, M. (2000). Survival in beta-thalassaemia major in the UK: Data from the UK Thalassaemia Register. Lancet, 355(9220), 2051-2052. http://dx.doi.org/10.1016/S0140-6736(00)02357-6

Olivieri, N. F. (1999). The beta-thalassemias. N Engl J Med, 341(2), 99-109. http://dx.doi.org/10.1056/NEJM19 9907083410207

Quinones, M. A., Otto, C. M., Stoddard, M., Waggoner, A., \& Zoghbi, W. A. (2002). Recommendations for quantification of Doppler echocardiography: A report from the Doppler Quantification Task Force of the Nomenclature and Standards Committee of the American Society of Echocardiography. J Am Soc Echocardiogr, 15(2), 167-184. http://dx.doi.org/10.1067/mje.2002.120202

Rodrigues, A., Guimaraes-Filho, F. V., Braga, J. C., Rodrigues, C. S., Waib, P., Fabron-Junior, A., ... Okoshi, K. (2013). Echocardiography in thalassemic patients on blood transfusions and chelation without heart failure. Arq Bras Cardiol, 100(1), 75-81. http://dx.doi.org/10.1590/S0066-782X2013005000001

Rund, D., \& Rachmilewitz, E. (2005). Beta-thalassemia. N Engl J Med, 353(11), 1135-1146. http://dx.doi.org/10. 1056/NEJMra050436

Silvilairat, S., Sittiwangkul, R., Pongprot, Y., Charoenkwan, P., \& Phornphutkul, C. (2008). Tissue Doppler echocardiography reliably reflects severity of iron overload in pediatric patients with beta thalassemia. Eur J Echocardiogr, 9(3), 368-372.

Tanner, M. A., Galanello, R., Dessi, C., Westwood, M. A., Smith, G. C., Nair, S. V., ... Pennell, D. J. (2006). Myocardial iron loading in patients with thalassemia major on deferoxamine chelation. $J$ Cardiovasc Magn Reson, 8(3), 543-547. http://dx.doi.org/10.1080/10976640600698155

Telfer, P. T., Prestcott, E., Holden, S., Walker, M., Hoffbrand, A. V., \& Wonke, B. (2000). Hepatic iron concentration combined with long-term monitoring of serum ferritin to predict complications of iron overload in thalassaemia major. Br J Haematol, 110(4), 971-977. http://dx.doi.org/10.1046/j.1365-2141. 2000.02298.x

Walker, J. M., \& Nair, S., (2010). Detection of the cardiovascular complications of thalassemia by echocardiography. Ann N Y Acad Sci, 1202, 165-172. http://dx.doi.org/10.1111/j.1749-6632.2010.05643.x

Wood, J. C. (2009). Cardiac complications in thalassemia major. Hemoglobin, 33(Suppl 1), S81-86. http://dx.doi.org/10.3109/03630260903347526

Yaprak, I., Aksit, S., Ozturk, C., Bakiler, A. R., Dorak, C., \& Turker, M. (1998). Left ventricular diastolic abnormalities in children with beta-thalassemia major: A Doppler echocardiographic study. Turk J Pediatr, 40(2), 201-209.

\section{Copyrights}

Copyright for this article is retained by the author(s), with first publication rights granted to the journal.

This is an open-access article distributed under the terms and conditions of the Creative Commons Attribution license (http://creativecommons.org/licenses/by/3.0/). 